\title{
Design, preparation and in vitro characterizations of fluconazole loaded nanostructured lipid carriers
}

\author{
Amanda Velinna Fernandes ${ }^{1}$, Chinna Raja Pydi' ${ }^{1}$, Ruchi Verma ${ }^{\circledR 2}$, Jobin Jose ${ }^{3}$, Lalit Kumar ${ }^{1, *}$
}

\begin{abstract}
${ }^{1}$ Department of Pharmaceutics, Manipal College of Pharmaceutical Sciences, Manipal Academy of Higher Education, Manipal, Udupi, Karnataka, India, ${ }^{2}$ Department of Pharmaceutical Chemistry, Manipal College of Pharmaceutical Sciences, Manipal Academy of Higher Education, Manipal, Udupi, Karnataka, India, ${ }^{3}$ Department of Pharmaceutics, NGSM Institute of Pharmaceutical Sciences, NITTE Deemed to be University, Paneer, Deralakatte, Mangalore, India
\end{abstract}

\begin{abstract}
Present study was aimed to prepare and characterize fluconazole loaded nanostructured lipid carriers (FLZ-NLCs) for the treatment of fungal infections. Fungal infections are tremendously widespread and are the often faced dermatological condition worldwide. FLZ-NLCs was prepared by ultrasonication emulsion technique using stearic acid (SA) as solid lipid, castor oil as liquid lipid and tween 20 as a surfactant. The mean diameter of optimized FLZ-NLCs were found to be $359.15 \pm 9.83 \mathrm{~nm}$. The drug content and entrapment efficiency of NLCs was found to be $102.97 \pm 7.45 \%$ and $87 \pm 0.59 \%$, respectively. In vitro drug release studies of FLZ-NLCs showed $37.34 \pm 2.08 \%$ drug release over a period of $72 \mathrm{~h}$. The above studies confirmed the prepared FLZ-NLCs may be useful for the treatment of fungal infections.
\end{abstract}

Keywords: Fluconazole. NLCs. Nanostructured lipid carriers. Fungal infections. Full factorial design. Design of experiment.

\section{INTRODUCTION}

The occurrence of superficial fungal infections have been globally increased, almost up to 40.0 million people suffer from this infection in developed as well as under developed countries. Fungal infections can cause deteriorating immune system with its progresses (Havlickova, Czaika, Friedrich, 2008; Ameen, 2010). Treating fungal infections via topical route provides several advantages, such as reduction in adverse effects of antifungal agents, site specific delivery, high patient compliance and efficacious treatment. There are various topical antifungal agents used in treating dermatological skin problems. They mainly includes azoles, allylamine/ benzylamines and polyenes (Güngör, Erdal, Aksu, 2013). Feasibility of a topical formulation solely depends on its permeation through the target site and also on the availability of drug concentration levels in the skin.

Novel drug delivery systems include colloidal systems, vesicular carriers and nanoparticles enhances

\footnotetext{
*Correspondence: L. Kumar. Department of Pharmaceutics, Manipal College of Pharmaceutical Sciences, Manipal Academy of Higher Education, Manipal 576 104, Karnataka, India. Phone: +91 98801 20144. E-Mail: lk.kundlas@gmail.com
}

the topical delivery of antifungals into the skin (Lee, Maibach, 2006). The nanoparticulate carrier systems such as nanostructured lipid carriers (NLCs) are the second generation of lipid particles, specially designed to overpower solid lipids nanoparticles (SLNs) with respect to their limitations. NLCs are blend of solid and liquid lipids. They are less toxic in nature as the lipids used are approved as safe (GRAS) and the nano range of particles enhance the penetration into stratum corneum. They exhibit a controlled release profile and in the recent years these nanoparticulate carrier systems such as SLNs and NLCs have been formulated as an effective carrier for antifungal compounds (Souto et al., 2004; Gupta, Vyas, 2012). NLC reduces the systemic absorption of the drugs and is an excellent carrier for irritant drugs at high concentrations (Li et al., 2008; Selvamuthukumar, Velmurugan, 2012). On topical application, the lipids tend to adhere to the skin due to their occlusive property that leads to increased skin hydration effect. NLCs have the ability to scatter light owing to the structural imperfections which can be used to incorporate light sensitive drugs in them (Sanad et al., 2010).

Fluconazole (FLZ) belongs to a class of compounds named as fluorobenzenes (Fluconazole, 2017). It is a 
synthetic antifungal agent belonging to biopharmaceutical classification system (BCS) class III, which has a log P value of 0.4 . It is widely used antifungal drug for most of the superficial and invasive dermatological conditions (Gaikwad et al., 2012). It differs in its pharmacokinetic profile when compared to imidazoles. The structure consists of two triazole rings, which render the drug to be more hydrophilic in nature when compared to other azoles. The halogenated phenyl ring is responsible for antifungal activity. Fluconazole is commercially available as oral tablets and injections which has disadvantages such as nausea, vomiting, bloating, loss of appetite, headache, etc. (Helal et al., 2012; Sawant, Khan, 2017). But, oral formulations cannot reach the required concentration of drug in the body to deactivate the fungi (Kumar et al., 2013) and another issue associated with the oral formulations is avoidance of their administration during pregnancy (Merkus, 1990). Parenteral are less preferable by the patients due to related pain on the site of administration and privacy which causes lack of patient compliance.

In the last few years, researchers have focused more on the lipid nanoparticles (such as SLNs, NLCs, niosomes, liposomes, ethosomes, etc.) of antifungals to avoid their side effects and to improve their efficacy (Trombino, Mellace, Cassano, 2016; Behtash, Nafisi, Maibach, 2017; Soliman, 2017; Wolf et al., 2017). Hence, in the present study, to overcome the problems associated with FLZ, the NLC system for topical delivery of FLZ has been proposed. The available literature justifies that FLZ loaded NLCs are limited. The NLCs formulation shows a high amount of drug accumulation in the skin which is recommended for the fungal treatment. Thus, NLCs are providing a good targeting effect and it also has proved to be a promising carrier for topical delivery of drugs exhibiting antigungal activity (Gupta, Vyas, 2012). The aim of the present study was to develop and characterize FLZ loaded NLCs.

\section{MATERIAL AND METHODS}

\section{Material}

FLZ was received as a gift sample from Ipca Laboratories, Mumbai, India. Stearic acid and potassium dihydrogen ortho phosphate were purchased from Finar Limited, Ahmedabad, India. Castor oil was procured from Jayant Agro Organics, Mumbai, India. Tween 20 was found from Encube Ethicals Pvt. Ltd., Goa, India. Poloxamer 188 was obtained as gift sample from Signet Chemical Corporation Pvt. Ltd., Mumbai, India.
Methanol was obtained from Lobort Fine Chem Pvt. Ltd., Surat, India. Oleic acid and olive oil were purchased from Sigma-Aldrich Chemie, USA. Sodium hydroxide was obtained from HiMedia Laboratories Pvt. Ltd., Mumbai, India.

\section{Methods}

\section{Selection of lipids, surfactants and method for the preparation of NLCs}

Lipids, surfactants and method for preparation of NLCs were selected on the basis of the following studies:

\section{Screening of solid lipids}

The solid lipid (100 mg) was taken in a glass ria vial. Then the heat was applied to $10^{\circ} \mathrm{C}$ greater than the actual temperature of the lipid. FLZ was added in the molten mass of lipid in the increment of $1 \mathrm{mg}$ until the molten lipid reached a saturated state. The solubility of FLZ was determined in two solid lipids such as stearic acid (SA) and glyceryl monostearate (GMS). Then the amount of FLZ taken up by $1 \mathrm{~g}$ of solid lipid was calculated.

\section{Screening of liquid lipids (oils)}

The solubility of FLZ was determined in various liquid lipids (castor oil, oleic acid and olive oil) by adding FLZ in the increment of $0.5 \mathrm{mg}$ in $0.5 \mathrm{~mL}$ of the liquid lipids in microcentrifuge tubes. Then the micro centrifuge tubes were vortex for 2 min and physically observed. The procedure was continued with the addition of $0.5 \mathrm{mg}$ increment of drug until it no longer dissolved. Then the amount of FLZ which can be taken up by $1 \mathrm{~g}$ of liquid lipid was calculated.

\section{Screening of surfactants and selection of method for the preparation of $\mathrm{NLCS}$}

Three emulsifying agents such as tween 20 , tween 80 and poloaxamer 188 were studied for their suitability. Few trials were performed with tween 20 , tween 80 and poloxamer 188 using microemulsion technique (Saez, Souza, Mansur, 2018) (as shown in Table I) and also few trials were performed with two surfactants such as tween 20 and tween 80 using ultrasonication emulsion technique (as shown in Table II). The surfactant which couldn't showed very promising results while using microemulsion technique was ignored during ultrasonication emulsion technique. The particle size, polydispersity index (PDI) and zeta potential of these trials were recorded and on the basis of the obtained results a suitable emulsifier and a method for the preparation of NLCs was chosen. 
Design, preparation and in vitro characterizations of fluconazole loaded nanostructured lipid carriers

TABLE I - Study of surfactants using microemulsion technique

\begin{tabular}{lcccccc}
\hline Surfactant & Concentration & $\begin{array}{c}\text { Amount of SA } \\
(\mathbf{m g})\end{array}$ & $\begin{array}{c}\text { Amount of } \\
\text { castor oil }(\boldsymbol{\mu L} \mathbf{L})\end{array}$ & $\begin{array}{c}\text { Particle size } \\
(\mathbf{n m})\end{array}$ & PDI & $\begin{array}{c}\text { Zeta potential } \\
(\mathbf{m V})\end{array}$ \\
\hline Poloxamer 188 & $2 \% \mathrm{w} / \mathrm{v}$ & 200 & 20 & 1813 & 0.414 & -19.6 \\
Tween 80 & $2 \% \mathrm{v} / \mathrm{v}$ & 200 & 20 & 817.9 & 0.560 & -3.9 \\
Tween 20 & $2 \% \mathrm{v} / \mathrm{v}$ & 200 & 20 & 1311 & 0.409 & -23.7 \\
\hline
\end{tabular}

Abbreviations: SA, stearic acid; and PDI, polydispersity index.

TABLE II - Study of surfactants using ultrasonication emulsion method

\begin{tabular}{lcccccc}
\hline Surfactant & $\begin{array}{c}\text { Concentration } \\
(\mathbf{\%} / \mathbf{v})\end{array}$ & $\begin{array}{c}\text { Amount of SA } \\
(\mathbf{m g})\end{array}$ & $\begin{array}{c}\text { Amount of } \\
\text { castor oil }(\boldsymbol{\mu L})\end{array}$ & $\begin{array}{c}\text { Particle size } \\
(\mathbf{n m})\end{array}$ & PDI & $\begin{array}{c}\text { Zeta potential } \\
(\mathbf{m V})\end{array}$ \\
\hline Tween 80 & 2 & 200 & 20 & 520.5 & 0.302 & -21.5 \\
Tween 20 & 2 & 200 & 20 & 362.4 & 0.216 & -21.6 \\
Tween 20 & 2 & 200 & 40 & 383.2 & 0.266 & -25.9 \\
Tween 20 & 2 & 300 & 40 & 169.1 & 0.481 & -20.4 \\
\hline
\end{tabular}

Abbreviations: SA, stearic acid; and PDI, polydispersity index.

\section{Drug-excipient compatibility studies}

\section{Fourier transform infrared spectroscopy (FTIR)}

Fourier transform infrared spectroscopy (FTIR) studies were performed using FTIR spectrophotometer (FTIR-8300, Shimadzu Corporation, Kyoto) to identify the compatibility of FLZ with SA. The spectrum was recorded using $\mathrm{KBr}$ pellet method in the range of $4000-400 \mathrm{~cm}^{-1}$. The physical mixture (PM) of FLZ and SA were stored at $40{ }^{\circ} \mathrm{C}$ for 15 days and after the specified time the samples were analysed with FTIR spectrophotometer. The obtained results were compared with FLZ and SA results to confirm the compatibility. After analysis, the spectrum were recorded using IR solution v.1.2 software (Kumar et al., 2013; Dutta et al., 2018).

\section{Attenuated total reflection Fourier transform infrared spectroscopy (ATR-FTIR)}

ATR-FTIR studies were performed using attenuated total reflectance (ATR) mode on a Bruker Vertex 70 (Bruker Daltonik GmbH, Germany) spectrometer equipped with a platinum ATR, Bruker Diamond Type A225/Q to identify the compatibility of FLZ with excipients. The spectrum of FLZ, SA, tween 20 (TW), castor oil (CO), physical mixture of SA and FLZ (SFLZ), physical mixture of SA, CO and FLZ (SCFLZ) and SA, CO, TW and FLZ (SCTFLZ) were recorded in the range of $4000-600 \mathrm{~cm}^{-1}$ at a resolution speed to $8 \mathrm{~cm}^{-1}$. All the physical mixtures before ATR-FTIR studies were stored at $40{ }^{\circ} \mathrm{C}$ for 15 days and after the specified time the samples were analysed with ATR-FTIR spectrophotometer. The obtained results were compared with FLZ, SA, CO and TW results to confirm the compatibility (Ewing et al., 2015; Ledeţi et al., 2015).

\section{Preparation of fluconazole nanostructured lipid carriers (NLCs)}

FLZ loaded NLCs were prepared by using constant temperature ultrasonication emulsion technique (Sharma et al., 2009; Kumar et al., 2016). All the ingredients were weighed accurately. The aqueous phase and the lipid phase were prepared separately. The lipid phase was containing SA (200 mg or $300 \mathrm{mg}$ ) as solid lipid, castor oil $(20 \mu \mathrm{L})$ as liquid lipid and FLZ (50 mg) whereas aqueous phase was containing surfactant (tween $20)$ in a sufficient quantity $(10 \mathrm{~mL})$ of milli $\mathrm{Q}$ water. A constant temperature was maintained at $10{ }^{\circ} \mathrm{C}$ above the actual melting point of solid lipid.

Aqueous phase $(10 \mathrm{~mL})$ was taken into a glass beaker $(25 \mathrm{~mL})$ which contains tween $20(2 \% \mathrm{v} / \mathrm{v}$ or $3 \% \mathrm{v} / \mathrm{v})$. The temperature of aqueous phase was adjusted equivalent to the temperature of lipid phase. Then the aqueous phase was added to the lipid phase and immediately sonicated using a probe sonicator (Ultrasonic Processor VC130, Sonics and Materials Inc., USA) with an amplitude of $21 \pm 2 \mathrm{~W}$ or $27 \pm 2 \mathrm{~W}$, pulses were maintained to $10 \mathrm{sec}$ and the sonication was carried for $10 \mathrm{~min}$ (Kumar et al., 2016). 


\section{Design and optimization of NLCs}

Two levels and three factors full factorial design was opted in the present study using Design Expert ${ }^{\circledR}$ v.9.0.5.1 software.

For NLCs, amount of solid lipid (stearic acid), surfactant concentration (tween 20) and sonication amplitude were considered as variables whereas particle size, polydispersity index and zeta potential were considered as responses. The levels of these variables are reported in Table III. On the basis of these levels and factors, software has suggested eight runs to be performed as reported in Table VI. The number of runs were performed and the responses were entered into the software.

TABLE III - Levels and variables of NLCs

\begin{tabular}{lcc}
\hline \multirow{2}{*}{ Variables } & \multicolumn{2}{c}{ Levels } \\
\cline { 2 - 3 } & $\mathbf{- 1}$ & $\mathbf{+ 1}$ \\
\hline Amount of lipid (mg) & 200 & 300 \\
Surfactant concentration $(\% \mathrm{v} / \mathrm{v})$ & 2 & 3 \\
Sonication amplitude $(\mathrm{W})$ & $21 \pm 2$ & $27 \pm 2$ \\
\hline
\end{tabular}

Abbreviation: W, watt

\section{Particle size, polydispersity index and zeta potential}

The particle size analysis of FLZ-NLCs formulations was performed using a Zetasizer (ZEN 3600, Malvern Instruments, Malvern, U.K.) which works on the principle of photon correlation spectroscopy (PCS). The PCS provides mean particle size so referred as z-average of the nanoformulations as well as the polydispersity index (PDI), which measures the width of the distribution. The particles size, polydispersity index and zeta potential was determined by diluting the formulations up to 50 fold with milli Q (Garud, Singh, Garud, 2012; Kumar et al., 2016; Srinivas et al., 2017).

\section{Drug content (DC) and entrapment efficiency (EE) of NLCs}

For total drug content in FLZ-NLCs formulation, $0.2 \mathrm{~mL}$ of the formulation and placebo NLCs were taken in two different microcentrifuge tubes and diluted with $0.8 \mathrm{~mL}$ of methanol which was centrifuged using cooling centrifuge (Sigma Laborzentrifugen $\mathrm{GmbH}, 3 \mathrm{~K} 30$, Germany) at $54,200 \mathrm{~g}$ for $30 \mathrm{~min}$ at $4{ }^{\circ} \mathrm{C}$. The supernatant was collected and filtered using a syringe filter $(0.22 \mu)$.
The absorbance of filtrate was measured using placebo NLCs formulation as a blank at $261 \mathrm{~nm}$ after 10 times dilution by using UV-Spectrophotometer (UV-1601PC, Shimadzu Corporation, Kyoto). The drug content (DC) of FLZ-NLCs was calculated using the formula given below:

Percent drug content $(\%)=\frac{\text { Actual Drug Content }(\mathrm{mg})}{\text { Theoretical Drug Content }(\mathrm{mg})} \times 100$

For presence of free drug in FLZ-NLCs formulation, $0.5 \mathrm{~mL}$ of the formulation and placebo NLCs were taken in two different microcentrifuge tubes and diluted with $0.5 \mathrm{~mL}$ of milli Q water which was centrifuged using cooling centrifuge (Sigma Laborzentrifugen $\mathrm{GmbH}$, $3 \mathrm{~K} 30$, Germany) at $54,200 \mathrm{~g}$ for $30 \mathrm{~min}$ at $4{ }^{\circ} \mathrm{C}$. The supernatant was collected and filtered using a syringe filter $(0.22 \mu)$. The absorbance of filtrate was measured at $261 \mathrm{~nm}$ by using UV - Spectrophotometer (UV-1601PC, Shimadzu Corporation, Kyoto) (Pardeike et al., 2011). The entrapment efficiency (EE) of FLZ-NLCs was calculated using the formula:

Percent drug entrapment $(\%)=\frac{\text { Total Drug Content }(\mathrm{mg})-\text { Free Drug }(\mathrm{mg})}{\text { Total Drug Content }(\mathrm{mg})} \times 100$

\section{In vitro release study}

In vitro drug release study FLZ-NLCs was performed in phosphate buffer $\mathrm{pH}$ 7.4. The study was carried out in $500 \mathrm{~mL}$ dissolution media using United States Pharmacopoeia (USP) Dissolution Apparatus II (Electrolab TDT-08L with temperature controller Electrolab ETC-11L, Electrolab Dissolution Tester (USP), Electrolab India Pvt. Ltd. Mumbai) by taking NLCs (4 mL) in dialysis bag (molecular cut off $12-14 \mathrm{kDa}$, HiMedia ${ }^{\circledR}$ Laboratories Pvt. Ltd., Mumbai). Throughout the study, the stirring speed and the temperature were maintained at $50 \mathrm{rpm}$ and $37 \pm 0.5^{\circ} \mathrm{C}$, respectively. Sink conditions were maintained by collecting $2 \mathrm{~mL}$ samples and replacing with the same volume of fresh dissolution media at pre-decided time intervals (i.e., $0,0.5,1,2,3,4,8,12,24,36,48$ and $72 \mathrm{~h}$ ). The collected samples were passed through $0.22 \mu$ membrane filter and absorbance was measured at $261 \mathrm{~nm}$ (Srinivas et al., 2017).

\section{RESULTS AND DISCUSSION}

\section{Selection of lipids, surfactants and method for the preparation of NLCs}

\section{Screening of solid lipids and liquid lipids}

Solubility of FLZ was observed in SA and GMS. The highest solubility of FLZ was found in SA as depicted in 
Figure 1A. These results are also supported by the earlier research on FLZ (Moazeni et al., 2016; Kelidari et al., 2017). The criteria for selecting the excipients was also based on its non-irritancy, pharmaceutical acceptance, non-sensitivity towards the skin and bear GRAS status (generally regarded as safe) (Gaba et al., 2015). The liquid lipids were physically observed for their homogeneity. FLZ showed a higher solubility in castor oil when compared to olive oil and oleic acid (shown in Figure 1B). On the basis of solubility studies of lipids, SA was selected as solid lipid and $\mathrm{CO}$ as the liquid lipid for the preparation of FLZ-NLCs. In this study, $20 \mu \mathrm{L}$ of CO was taken as it has been reported in the literature if the amount of oil increases in the NLCs then the chances of nanostructuring of NLC reduces as particle size increases (Kovacevic et al., 2011) and the possibility of oil separation also increases at the time of cooling process (Perez, 2005).

\section{Screening of surfactants and selection of method for the preparation of NLCS}

Surfactants improve the stability of the nanoformulations. Hydrophilic-lipophilic balance (HLB) values are considered as of prime importance in surfactant selection. Surfactants with low HLB values (3 to 6) are oil soluble and those who have high HLB values (8 to 18) are water soluble (Montenegro et al., 2016). Several types of surfactant have been used for the preparation of NLCs such as ionic, amphoteric, nonionic, etc. (Kovacevic et al., 2011). Non-ionic surfactants have low skin toxicity (Kovacevic et al., 2011), exhibit enhanced blood-compatibility (Balakrishnan, James, Jayakrishnan, 2005) and these can effectively inhibit the in vivo degradation of lipid matrix. Poly(ethylene oxide) chains on the non-ionic surfactants hamper the fastening of lipase/co-lipase complex which is accountable for lipid degradation (Olbrich, Müller, 1999; Olbrich, Kayser, Müller, 2002; Shah et al., 2015). Non-ionic surfactants are

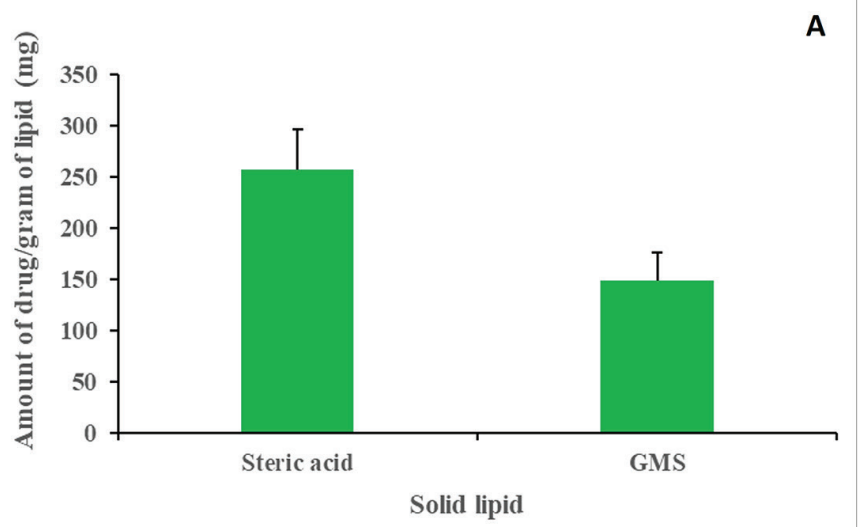

also preferred for topical preparations (Kovacevic et al., 2011). In this preparation of FLZ-NLCs, three non-ionic surfactants were studied namely poloxamer 188 , tween 80 and tween 20. The HLB value of poloxamer 188 is 29 , which is very high in comparison of tween 20 and tween 80 . HLB value of tween 80 is lesser than tween 20 that is 15. HLB value of tween 20 is 16.7. Surfactant screening study was carried out to study the effect of these three surfactants on particle size, PDI and zeta potential. The surfactant which reduces the particle size, reduces the PDI value and generates more surface charge is preferred (Kovacevic et al., 2011).

All three surfactants were studied using microemulsion technique (first technique for screening of surfactants) by keeping all other factors constant such as amount of solid lipid, amount of liquid lipid and concentration of surfactant. On the basis of obtained results, poloxamer 188 was eradicated from further study (using second technique such as ultrasonication emulsion technique) as it showed very high particle size compared to tween 20 and tween 80 . Tween 80 showed smaller particle size compared to tween 20 and poloxamer 188. But the NLCs prepared using tween 80 showed high PDI value and less zeta potential value.

For further screening study using second technique i.e. ultrasonication emulsion technique, tween 20 and tween 80 were selected. Tween 20 was selected as it showed high zeta potential, small particle size and low PDI with first technique (as presented in Table I) compared to poloxamer 188. Similarly, tween 80 was also preferred over poloxamer 188 , as it also showed smaller particle size with first technique (as reported in Table I) compared to tween 20 and poloxamer 188. It has also been reported in the earlier studies that poloxamer 188 produces bigger particle size in comparison of tween 20 and tween 80 that might be due to the high HLB value of poloxamer 188 (Das, Ng, Tan, 2012).

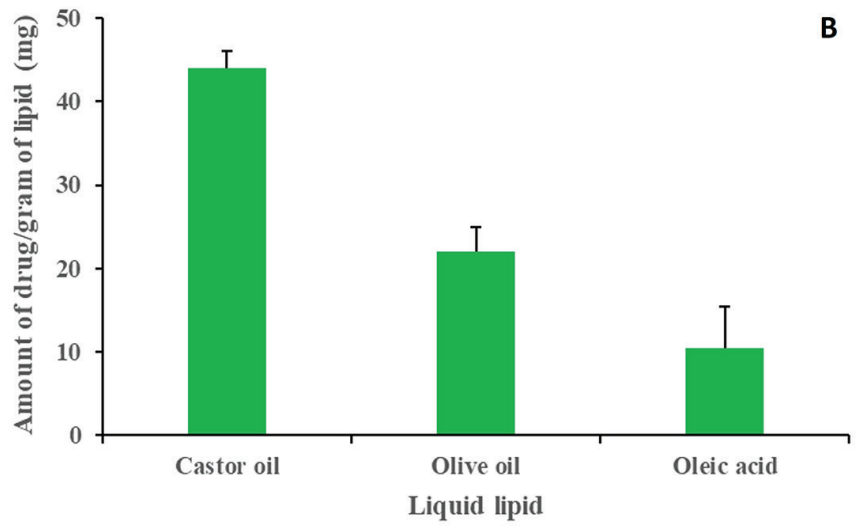

FIGURE 1 - Solubility of FLZ in lipids: (A) solid lipids and (B) liquid lipids (data presented as mean $\pm \mathrm{SD}, \mathrm{n}=3$ ). 
In ultrasonication emulsion technique, instrumental conditions were kept constant (such as sonication time, pulses and sonication amplitude) and the effect of tween 20 and tween 80 on particle size, PDI and zeta potential was studied. As reported in Table II, tween 20 was found to be a suitable surfactant in meeting the requirements of FLZ-NLCs as the particle size was small, PDI value was found to be less and the charge on the surface of particles was also considerable. As reported in the literature, usually the zeta potential value more than 20 or less than $-20 \mathrm{mV}$ is preferable for a physically stable nanoformulation (Das et al., 2012). Similarly, smaller PDI value is preferable (more towards 0 which indicates monodisperse nature of populations) (Das, $\mathrm{Ng}$, Tan, 2012). Most of the investigators prefer PDI values less than 0.3 , but less than 0.5 is also acceptable (Kaur et al., 2008; Shah et al., 2014).

Furthermore, the particle size can be reduced with the alteration in the sonication conditions and increase in the surfactant concentration (Silva, et al., 2010; Das, $\mathrm{Ng}$, Tan, 2012; Kumar et al., 2016). Hence, tween 20 was chosen as the surfactant in formulating FLZ-NLCs and the ultrasonication emulsion method was used for the preparation of nanoparticles as it complied with our requirements.

\section{Drug-excipient compatibility studies}

\section{Fourier transform infrared spectroscopy (FTIR)}

FTIR spectrum of pure FLZ, SA and physical mixture were recorded in between 4000 to $400 \mathrm{~cm}^{-1}$ wavenumber. The spectra of essential functional groups of FLZ in physical mixture were analysed and compared with the spectra obtained in pure FLZ and SA to confirm the compatibility of FLZ with SA. FTIR spectra of FLZ, SA and physical mixture are reported in Table IV.

As reported in Table IV, the main absorption peaks of FLZ (in FLZ sample) were found at $3111.18 \mathrm{~cm}^{-1}(\mathrm{~N}-\mathrm{H}$ stretching), $2958.80 \mathrm{~cm}^{-1}$ (C-H stretching), $1595.13 \mathrm{~cm}^{-1}$ $(\mathrm{C}=\mathrm{C}), 1510.26 \mathrm{~cm}^{-1}$ (triazole ring stretching), $1247.94 \mathrm{~cm}^{-1}$ (triazole ring stretching), $1139.93 \mathrm{~cm}^{-1}$ (C-F stretching), $1016.86 \mathrm{~cm}^{-1}$ (C-OH stretching), $966.34 \mathrm{~cm}^{-1}(\mathrm{O}-\mathrm{H}$ stretching and $572.86 \mathrm{~cm}^{-1}$ ( $\beta-\mathrm{CF}$ ) (Gu and Jiang, 1995; Cyr et al., 1996; Kumar et al., 2013). The absorbance peaks of SA (in SA sample) were noticed at $2927.94 \mathrm{~cm}^{-1}$, $2852.72 \mathrm{~cm}^{-1}$ (C-H stretching), $2673.34 \mathrm{~cm}^{-1}(\mathrm{O}-\mathrm{H}$ stretching), $1707 \mathrm{~cm}^{-1}(\mathrm{C}=\mathrm{O}$ stretching $), 1411.89 \mathrm{~cm}^{-1}$ (C-OH stretching), $1099.43 \mathrm{~cm}^{-1}(\mathrm{C}-\mathrm{OH}$ stretching) and $941.26 \mathrm{~cm}^{-1}$ (O-H stretching) (Kimura, Umemura, Takenaka, 1986; Kamata, Umemura, Takenata, 1987; Nair, Pradeep, MacLaren, 2004). The physical mixture (PM) of FLZ and SA showed absorption peaks at $3111.18 \mathrm{~cm}^{-1}$
TABLE IV - Fourier transform infrared spectroscopy studies of FLZ, SA and physical mixture

\begin{tabular}{lccc}
\hline \multirow{2}{*}{$\begin{array}{l}\text { Vibration } \\
\text { mode }\end{array}$} & \multicolumn{3}{c}{ Frequency $\left(\mathbf{c m}^{-1}\right)$} \\
\cline { 2 - 4 } N-H Str & 3111.18 & SA & PM \\
C-H Str & 2958.80 & --- & 3111.18 \\
C-H Str & --- & 2927.94 & 2956.87 \\
C-H Str & ---- & 2852.72 & 2852.72 \\
O-H Str & ---- & 2673.34 & ---- \\
C=O Str & ---- & 1707.00 & 1708.93 \\
C=C Str & 1595.13 & --- & 1595.13 \\
Triazole ring Str & 1510.26 & --- & 1510.26 \\
C-OH Str & ---- & 1411.89 & 1423.47 \\
Triazole ring Str & 1247.94 & ---- & 1247.94 \\
C-F Str & 1139.93 & --- & 1138.00 \\
C-OH Str & 1016.86 & 1099.43 & 1011.86 \\
O-H Str & 966.34 & 941.26 & 966.34 \\
$\beta-C F$ & 572.86 & --- & 572.86 \\
\hline Abbreviation
\end{tabular}

Abbreviations: FLZ, fluconazole; SA, stearic acid; and PM, Physical mixture of FLZ and SA.

(for N-H stretching), $2956.87 \mathrm{~cm}^{-1}$ and $2852.72 \mathrm{~cm}^{-1}$ (for $\mathrm{C}-\mathrm{H}$ stretching), $1708.93 \mathrm{~cm}^{-1}(\mathrm{C}=\mathrm{O}$ stretching), $1595.13 \mathrm{~cm}^{-1}(\mathrm{C}=\mathrm{C}), 1510.26 \mathrm{~cm}^{-1}$ (triazole ring stretching), $1423.47 \mathrm{~cm}^{-1}$ (C-OH stretching), $1247.94 \mathrm{~cm}^{-1}$ (triazole ring stretching), $1138 \mathrm{~cm}^{-1}$ (C-F stretching), $101186 \mathrm{~cm}^{-1}$ (for C-OH stretching), $966.34 \mathrm{~cm}^{-1}$ (O-H stretching) and $572.86 \mathrm{~cm}^{-1}(\beta-\mathrm{CF})$. All the important characteristic spectra of FLZ and SA were found in the PM of FLZ and SA which confirms the compatibility of FLZ with SA.

\section{Attenuated total reflection Fourier transform infrared spectroscopy (ATR-FTIR)}

ATR-FTIR spectrum of pure FLZ, SA and physical mixture were recorded in between 4000 to $600 \mathrm{~cm}^{-1}$ wavenumber. The essential functional group peaks in physical mixtures [physical mixture of SA and FLZ (SFLZ), physical mixture of SA, CO and FLZ (SCFLZ) and physical mixture of SA, CO, TW and FLZ (SCTFLZ) ] were analysed and compared with the spectra obtained in the pure FLZ, SA, tween 20 (TW), castor oil (CO) to confirm the compatibility of FLZ with excipients used to develop the formulation. FTIR spectra of FLZ, SA and physical mixtures are reported in Table $\mathrm{V}$.

In FLZ, the triazole group was confirmed with the presence of C-H stretching mode at $3105.00 \mathrm{~cm}^{-1}$ which was also found in the SFLZ, SCFLZ and SCTFLZ at 
Design, preparation and in vitro characterizations of fluconazole loaded nanostructured lipid carriers

TABLE V - Attenuated total reflection Fourier transform infrared spectroscopy studies of FLZ, SA and physical mixtures

\begin{tabular}{|c|c|c|c|c|c|c|c|}
\hline \multirow{2}{*}{$\begin{array}{l}\text { Vibration } \\
\text { mode }\end{array}$} & \multicolumn{7}{|c|}{ Frequency $\left(\mathrm{cm}^{-1}\right)$} \\
\hline & FLZ & SA & TW & $\mathrm{CO}$ & SFLZ & SCFLZ & SCTFLZ \\
\hline O-H Str. & --- & ---- & 3481.98 & ---- & --- & ---- & 3442.62 \\
\hline C-H Str & 3105.00 & ---- & ---- & ---- & 3116.05 & 3118.05 & 3117.78 \\
\hline C-H Str & 2956.31 & ---- & ---- & ---- & 2956.32 & 2955.99 & ---- \\
\hline C-H Str. & ---- & 2914.20 & 2921.68 & ---- & 2914.81 & 2916.09 & 2918.13 \\
\hline C-H Str. & ---- & 2847.17 & 2861.48 & ---- & 2847.54 & 2849.02 & 2852.11 \\
\hline -C-H- Str. & ---- & ---- & ---- & 2924.61 & ---- & 2916.09 & 2918.13 \\
\hline$-\mathrm{C}=\mathrm{O}$ Str. & ---- & ---- & 1734.66 & 1742.80 & ---- & 1744.21 & 1740.24 \\
\hline $\mathrm{C}=\mathrm{O} \mathrm{Str}$ & ---- & 1696.36 & ---- & ---- & 1698.97 & 1701.78 & 1703.78 \\
\hline $\mathrm{C}=\mathrm{C}$ Str. & 1616.77 & ---- & ---- & ---- & 1616.55 & 1616.59 & 1616.93 \\
\hline Triazole ring str. & 1502.33 & ---- & ---- & ---- & 1514.48 & 1514.47 & 1513.84 \\
\hline C-F Str & 1274.31 & ---- & ---- & ---- & 1270.68 & 1269.84 & 1270.98 \\
\hline Triazole ring Str. & 1246.47 & ---- & ---- & ---- & 1250.27 & 1250.82 & 1250.07 \\
\hline $\mathrm{C}-\mathrm{OH} \mathrm{Str}$ & 1016.86 & ---- & ---- & ---- & 1011.61 & 1010.57 & 1011.19 \\
\hline
\end{tabular}

Abbreviations: FLZ, fluconazole; SA, stearic acid; TW, Tween 20; CO, Castor oil; SFLZ, physical mixture of SA and FLZ; SCFLZ, physical mixture of SA, CO and FLZ; and SCTFLZ, Physical mixture of SA, CO, TW and FLZ.

$3116.05 \mathrm{~cm}^{-1}, 3118.05 \mathrm{~cm}^{-1}$ and $3117.78 \mathrm{~cm}^{-1}$, respectively. Furthermore, the presence of triazole ring in FLZ was confirmed with the presence of absorbance peaks at $1502.33 \mathrm{~cm}^{-1}$ and $1246.47 \mathrm{~cm}^{-1}$. The absorbance bands were further confirmed in SFLZ with the absorbance bands at $1514.48 \mathrm{~cm}^{-1}$ and $1250.27 \mathrm{~cm}^{-1}$. These absorbance bands were also present in SCFLZ at $1514.47 \mathrm{~cm}^{-1}$ and $1250.82 \mathrm{~cm}^{-1}$. The same absorbance bands were also found in SCTFLZ at $1513.84 \mathrm{~cm}^{-1}$ and $1250.07 \mathrm{~cm}^{-1}$. In fluconazole structure, 2,4 - Difluorobenzyl group is also present which showed its absorbance band for C-F stretching at $1274.31 \mathrm{~cm}^{-1}$ in pure FLZ sample; and at $1270.68 \mathrm{~cm}^{-1}, 1269.84 \mathrm{~cm}^{-1}$ and $1270.98 \mathrm{~cm}^{-1}$ in SFLZ, SCFLZ and SCTFLZ, respectively. The absorbance bands of $\mathrm{C}=\mathrm{C}$ stretching were present at $1616.77 \mathrm{~cm}^{-1}$, $1616.55 \mathrm{~cm}^{-1}, 1616.59 \mathrm{~cm}^{-1}$ and $1616.93 \mathrm{~cm}^{-1}$ in pure FLZ, SFLZ, SCFLZ and SCTFLZ, respectively. These absorbance bands of $\mathrm{C}=\mathrm{C}$ stretching confirmed the presence of aromatic ring of FLZ in all the samples. The presence of hydroxyl group of FLZ was also found in the pure FLZ, SFLZ, SCFLZ and SCTFLZ as C-OH stretching at absorbance bands $1016.86 \mathrm{~cm}^{-1}, 1011.61 \mathrm{~cm}^{-1}$, $1010.57 \mathrm{~cm}^{-1}$ and $1011.19 \mathrm{~cm}^{-1}$, respectively. These results of IR confirms the compatibility of FLZ with the used excipients (Gu and Jiang, 1995; Cyr et al., 1996; Kumar et al., 2013).

The presence of SA in the samples was inveterate with the important absorption peaks of C-H stretching at two places. One of C-H asymmetric stretching at absorbance bands $2914.20 \mathrm{~cm}^{-1}, 2914.81 \mathrm{~cm}^{-1}$, $2916.09 \mathrm{~cm}^{-1}$ and $2918.13 \mathrm{~cm}^{-1}$, in pure SA, SFLZ, SCFLZ and SCTFLZ, respectively. Second of C-H symmetric stretching at absorbance bands $2847.17 \mathrm{~cm}^{-1}$, $2847.54 \mathrm{~cm}^{-1}, 2849.02 \mathrm{~cm}^{-1}$ and $2852.11 \mathrm{~cm}^{-1}$, in pure SA, SFLZ, SCFLZ and SCTFLZ, respectively. The C $=\mathrm{O}$ stretching absorbance band of hydrogen bonded dimer was appeared at $1696.36 \mathrm{~cm}^{-1}, 1698.97 \mathrm{~cm}^{-1}, 1701.78 \mathrm{~cm}^{-1}$ and $1703.78 \mathrm{~cm}^{-1}$ in pure SA, SFLZ, SCFLZ and SCTFLZ, respectively (Kimura et al., 1986; Kamata, Umemura, Takenata, 1987; Nair, Pradeep, MacLaren, 2004).

The presence of $\mathrm{CO}$ in the samples was confirmed with the two absorbance bands. One of $-\mathrm{C}-\mathrm{H}$ - stretching at absorbance bands $2924.61 \mathrm{~cm}^{-1}, 2916.09 \mathrm{~cm}^{-1}$ and $2918.13 \mathrm{~cm}^{-1}$ in pure CO, SCFLZ and SCTFLZ, respectively. Second of $-\mathrm{C}=\mathrm{O}$ stretching for the presence of methyl ricinoleate at absorbance bands $1742.80 \mathrm{~cm}^{-1}$, $1744.21 \mathrm{~cm}^{-1}$ and $1740.24 \mathrm{~cm}^{-1}$ in pure CO, SCFLZ and SCTFLZ, respectively (Zamiri et al., 2011; Narwal et al., 2015).

The presence of TW in the samples was inveterate with the absorbance bands for $-\mathrm{OH}$ stretching at $3481.98 \mathrm{~cm}^{-1}$ and $3442.62 \mathrm{~cm}^{-1}$ in pure TW and SCTFLZ, respectively. Three more absorbance bands in pure TW was recoded at $2921.68 \mathrm{~cm}^{-1}, 2861.48 \mathrm{~cm}^{-1}$ and $1734.66 \mathrm{~cm}^{-1}$ which confirms the presence of $\mathrm{C}-\mathrm{H}$ asymmetric stretching, $\mathrm{C}-\mathrm{H}$ symmetric stretching and $-\mathrm{C}=\mathrm{O}$ stretching, 
respectively (Balakrishnan, James, Jayakrishnan, 2005). These three peaks were slightly shifted and overtone in physical mixtures with the same functional groups peak in lipids as the same functional groups are present in the used lipids (Balakrishnan, James, Jayakrishnan, 2005).

The ATR-FTIR study confirmed the compatibility of FLZ with excipients used for the formulation development.

\section{Optimization and characterisation of NLCs}

Full factorial design was used for the optimization of NLCs. Two level full factorial design $\left(2^{3}\right)$ have suggested total of eight batches of formulation. The software suggested formulation batches were performed and collected responses (particle size, PDI and zeta potential) were put into the software. The obtained responses for the eight formulation batches are recorded in Table VI.

\section{Particle size, PDI and zeta potential}

The particle size, PDI and zeta potential of FLZNLCs were found to be in the range of 259.50 to 418.00 $\mathrm{nm}, 0.165$ to 0.475 and -21.00 to $-14.30 \mathrm{mV}$, respectively. The maximum particle size of FLZ-NLCs was found to be $418.00 \mathrm{~nm}$ which is parallel in the line of lipid nanoparticles prepared using stearic acid and tween 20 in the earlier research (Shah et al., 2014). The PDI values of all the formulations were found to be less than 0.5 which is considered to be appropriate and results indicates the homogeneous distribution of prepared FLZ-NLCs (Shah et al., 2014; Wolf et al., 2017). The zeta potential values were also found to be in the similar range of the SLNs prepared earlier using stearic acid and tween 20 by the other investigates (Shah et al., 2014).
As depicted in Figure 2X, particle size was found to be decreased with increase of sonication amplitude. These results are also supported by the earlier findings (Silva et al., 2010; Das, Ng, Tan, 2012). Surfactant concentration had shown positive effect on the particle size i.e., increase in the concentration of tween 20 there was increase in particle size. This may be due to the several reasons. First reason may be the viscosity of the dispersion medium. The increase in viscosity of the dispersion medium by increase in the concentration of tween 20 which may form rigid layer at the surface of particles and may increase the particle size (Elfiyani, Amalia, Pratana, 2017). Second reason may be tween 20 is acting as amphiphilic molecules which are deposited at the surface of particles resulting in increment of particle size (Asasutjarit et al., 2007; Asasutjarit et al., 2013). Amount of solid lipid did not show any effect on the particle size. Furthermore, the effect of variables on particle size was studied using the eq 1 .

Particle Size $=368.26+15.59 \mathrm{~B}-28.91 \mathrm{C}+13.41 \mathrm{AB}-$ $8.89 \mathrm{AC}+22.96 \mathrm{BC}+18.49 \mathrm{ABC}$

where, $\mathrm{A}, \mathrm{B}$ and $\mathrm{C}$ are the coded factors for the amount of solid lipid, concentration of tween 20 and sonication amplitude.

Although, the effect of amount of solid lipid was not found on the particle size, but with other variables such as concentration of tween 20 and sonication amplitude it also revealed some interactive effect on the particle size. As shown in eq. 1, amount of solid lipid and concentration of tween 20 collectively presented positive effect (means increase of particle size) on the particle size which may be due to the main effect of surfactant concentration

TABLE VI - Formulation design with variables and responses of FLZ-NLCs

\begin{tabular}{|c|c|c|c|c|c|c|}
\hline \multirow[b]{2}{*}{$\begin{array}{l}\text { Formulation } \\
\text { code }\end{array}$} & \multicolumn{3}{|c|}{ Variables } & \multicolumn{3}{|c|}{ Responses } \\
\hline & $\begin{array}{l}\text { Amount of } \\
\text { lipid (mg) }\end{array}$ & $\begin{array}{c}\text { Surfactant } \\
\text { concentration } \\
(\% \mathrm{v} / \mathrm{v})\end{array}$ & $\begin{array}{c}\text { Sonication } \\
\text { amplitude } \\
\text { (W) } \\
\end{array}$ & $\begin{array}{l}\text { Particle size } \\
\quad(\mathrm{nm})\end{array}$ & PDI & $\begin{array}{c}\text { Zeta potential } \\
(\mathrm{mV})\end{array}$ \\
\hline NLC 1 & 200 & 2 & $21 \pm 2$ & 391.10 & 0.181 & -17.40 \\
\hline NLC 2 & 200 & 2 & $27 \pm 2$ & 342.10 & 0.209 & -16.50 \\
\hline NLC 3 & 200 & 3 & $21 \pm 2$ & 386.50 & 0.413 & -18.00 \\
\hline NLC 4 & 200 & 3 & $27 \pm 2$ & 355.40 & 0.203 & -15.60 \\
\hline NLC 5 & 300 & 2 & $21 \pm 2$ & 418.00 & 0.197 & -18.60 \\
\hline NLC 6 & 300 & 2 & $27 \pm 2$ & 259.50 & 0.284 & -14.30 \\
\hline NLC 7 & 300 & 3 & $21 \pm 2$ & 393.10 & 0.165 & -14.80 \\
\hline NLC 8 & 300 & 3 & $27 \pm 2$ & 400.40 & 0.475 & -21.00 \\
\hline
\end{tabular}

Abbreviations: PDI, polydispersity index and W, watt. 
on particle size. Similarly, amount of solid lipid and sonication amplitude collectively revealed negative effect (means reduced particle size) on particle size which again may be due to sonication amplitude only.

As reported in Table VII, the regression coefficient $\left(r^{2}\right)$ of equation (1) was found to be 0.999 which confirmed the strong relation between the variables and responses. The $\mathrm{F}$ value of linear model for the particle size was found to be 1400.340. All the variables and selected model were found to be significant $(\mathrm{p}<0.05)$ for particle size as stated by ANOVA. The variables $\mathrm{B}, \mathrm{C}, \mathrm{AB}, \mathrm{AC}, \mathrm{BC}$ and $\mathrm{ABC}$ were found to be significant $(\mathrm{p}<0.05)$ with the $\mathrm{p}$-values $0.021,0.011,0.024,0.037,0.014$ and 0.018 , respectively. The signal to noise ratio was estimated with the adeq precision value and which was also found to be good with the value 116.89 .

As illustrated in Figure 2Y, PDI value found to be increased with increase of amount of solid lipid, concentration of tween 20 and sonication amplitude. The amount of solid lipid exhibited very least effect on PDI and concentration of tween 20 indicated highest effect on PDI compared to the sonication amplitude. An increase in PDI value with increased concentration of tween 20 was found. This may be due to the non-uniform thickness of surfactant layers on the surface of particles which affects the shape of particles. Sonication amplitude also showed some positive effect on PDI (increase of PDI values) that may be due to the uneven shape of particles. Furthermore the effect of variables on PDI was studied using the eq 2.

$\mathrm{PDI}=0.27+0.014 \mathrm{~A}+0.048 \mathrm{~B}+0.027 \mathrm{C}+0.072 \mathrm{AC}+$

$0.058 \mathrm{ABC}$

where, $\mathrm{A}, \mathrm{B}$ and $\mathrm{C}$ are the coded factors for the amount of solid lipid, concentration of tween 20 and sonication amplitude.
As presented in Table VII, the regression coefficient $\left(\mathrm{r}^{2}\right)$ of equation (2) was found to be 0.994 which also confirmed the strong relation between the variables and responses. The $\mathrm{F}$ value of linear model for PDI was found to be 64.100 . Few variables such as $\mathrm{B}, \mathrm{C}$ and $\mathrm{ABC}$; and selected model were found to be significant $(p<0.05)$ for PDI as stated by ANOVA. The variables B, C and ABC were found to be significant $(\mathrm{p}<0.05)$ with the $\mathrm{p}$-values $0.016,0.047$ and 0.011 , respectively. The variable $A$ was found to be non-significant $(p>0.05)$ whereas interactive variable $A B$ was found to be significant $(p<0.01)$ with $\mathrm{p}$-value 0.007 . The signal to noise ratio was estimated with the adeq precision value and which was also found to be good with the value 21.11.

As presented in Figure 2Z, amount of solid lipid, concentration of tween 20 and sonication amplitude does not have any direct effect on zeta potential which was further confirmed using the eq 3 . These results were found in the parallel line of SLNs prepared using stearic acid and tween 20 by other researchers (Shah et al., 2014). Preferably the prepared FLZ-NLCs are covered by nonionic surfactant (tween 20). It has been reported that if the lipid nanoparticles are covered by non-ionic surfactant may remain stable even having low zeta potential values (Martins et al., 2012; Shah et al., 2014). The stability of such type of particles were due to stearic stabilization rather than due to the electrostatic stabilization. The covering of particles with non-ionic surfactants decreases the mobility of the lipid nanoparticles and leading to lower the zeta potential values (Santander-Ortega et al., 2006; Martins et al., 2012; Shah et al., 2014).

Zeta potential $=-17.03-0.40 \mathrm{AB}-0.65 \mathrm{AC}-1.13 \mathrm{BC}-$ $1.50 \mathrm{ABC}$

where A, B and C are the coded factors for the amount
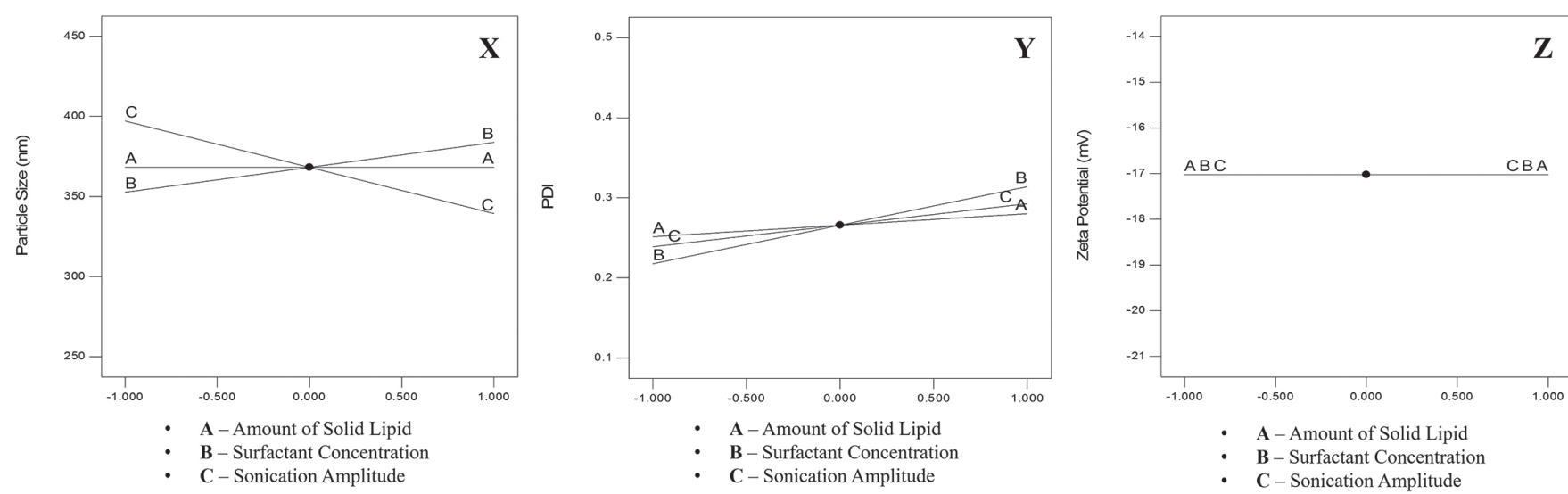

FIGURE 2 - Perturbation plots represents the effect of variables on responses: (X) Effect of variables on particle size; (Y) Effect of variables on PDI; (C) Effect of variables on zeta potential. 
TABLE VII - Results of coefficient estimate and regression analysis of variance (ANOVA)

\begin{tabular}{|c|c|c|c|c|c|c|c|c|c|}
\hline \multirow[b]{2}{*}{ Factors } & \multicolumn{3}{|c|}{ Particle size } & \multicolumn{3}{|c|}{ PDI } & \multicolumn{3}{|c|}{ Zeta potential } \\
\hline & $\begin{array}{c}\text { Coefficient } \\
\text { estimate }\end{array}$ & F-value & p-value & $\begin{array}{c}\text { Coefficient } \\
\text { estimate }\end{array}$ & F-value & p-value & $\begin{array}{c}\text { Coefficient } \\
\text { estimate }\end{array}$ & F-value & p-value \\
\hline Intercept & 368.260 & ---- & ---- & 0.270 & ---- & ---- & -17.03 & ---- & ---- \\
\hline A & ---- & ---- & ---- & 0.014 & 5.610 & 0.141 & ---- & ---- & ---- \\
\hline B & 15.590 & 925.050 & 0.021 & 0.048 & 62.890 & 0.016 & ---- & ---- & ---- \\
\hline $\mathrm{C}$ & -28.910 & 3182.610 & 0.011 & 0.027 & 19.610 & 0.047 & ---- & ---- & ---- \\
\hline $\mathrm{AB}$ & 13.410 & 684.910 & 0.024 & ---- & ---- & --- & -0.400 & 3.020 & 0.180 \\
\hline $\mathrm{AC}$ & -8.890 & 300.730 & 0.037 & 0.072 & 142.230 & 0.007 & -0.650 & 7.980 & 0.066 \\
\hline $\mathrm{BC}$ & 22.960 & 2007.480 & 0.014 & ---- & ---- & ---- & -1.130 & 23.920 & 0.016 \\
\hline $\mathrm{ABC}$ & 18.490 & 1301.270 & 0.018 & 0.058 & 90.170 & 0.011 & -1.500 & 42.520 & 0.007 \\
\hline $\mathrm{R}^{2}$ & & 0.999 & & & 0.994 & & & 0.963 & \\
\hline Adj $R^{2}$ & & 0.999 & & & 0.978 & & & 0.913 & \\
\hline Adeq precision & & 116.89 & & & 21.11 & & & 12.73 & \\
\hline
\end{tabular}

Note: A, B and C are amount of solid lipid, concentration of tween 20 and sonication amplitude, respectively. Abbreviations: PDI, polydispersity index.

of solid lipid, concentration of tween 20 and sonication amplitude.

As shown in Table VII, the regression coefficient $\left(\mathrm{r}^{2}\right)$ of equation (3) was found to be 0.963 which also confirmed the strong correlation between the variables and responses. The $\mathrm{F}$ value of linear model for the zeta potential was found to be 12.73. The variables (A, B and C) does not showed any effect. Variables AC, BC and selected model were found to be significant $(\mathrm{p}<0.05)$ for zeta potential as stated by ANOVA. The variable ABC was found to be significant ( $p$ $<0.01$ ) with the $p$-values 0.007 whereas variable $A B$ was found to be non-significant. The adeq precision value was also estimated to know signal to noise ratio and was also found to be good with the value 12.73 .

\section{Validation of optimized NLCs}

With the help of ANOVA, regression analysis, perturbation and surface response plots, the effect of variables on the responses was studied. The optimization criteria for FLZ-NLCs was set in the DoE software. On the basis of high desirability value (0.970) a software suggested formulation composition was selected for further studies. The software suggested FLZ-NLCs formulation was performed and the responses were recorded. The practically obtained responses were compared with the software predicted responses. On the basis of practically obtained and software predicted responses, the residual values were calculated (as shown in Table VIII).

Minimal errors were found in the obtained results which may be due to the trivial changes in the composition used for the preparation of FLZ-NLCs.

\section{Drug content (DC) and entrapment efficiency (EE) of NLCs}

Drug content and entrapment efficiency of an optimized FLZ-NLCs nanoformulation were found to be

TABLE VIII - Software suggest-ed and practically obtained results of FLZ-NLCs composition with desirability value

\begin{tabular}{|c|c|c|c|c|c|c|c|}
\hline & \multicolumn{3}{|c|}{ Variables } & \multicolumn{3}{|c|}{ Responses } & \multirow{2}{*}{ Desirability } \\
\hline & $\mathrm{A}(\mathrm{mg})$ & B (\%v/v) & $\mathrm{C}(\mathrm{W})$ & PS (nm) & PDI & $\mathrm{ZP}(\mathrm{mV})$ & \\
\hline Software Suggested & 252.56 & 2.01 & 26.98 & 300.00 & 0.247 & -15.87 & 0.970 \\
\hline Actual Obtained & 252.00 & 2.00 & 27.00 & $359.15 \pm 9.83$ & $0.236 \pm 0.01$ & $-19.25 \pm 0.35$ & \\
\hline Residual values & ---- & ---- & ---- & -59.15 & 0.011 & -3.38 & \\
\hline
\end{tabular}

Notes: (A) Amount of lipid; (B) Surfactant concentration; (C) Sonication amplitude and (W) Watt. Above results are presented as mean \pm SD, n=3. Abbreviations: PDI, polydispersity index; (PS) Particle size and (ZP) Zeta potential. 
$102.97 \pm 7.45 \%$ and $87.00 \pm 0.59 \%$, respectively. There is a high entrapment efficiency owing to the solid lipid matrix enclosing the liquid lipid in which the drug solubility is higher which ultimately increases the entrapment efficiency. The chosen lipids are mainly responsible in enhancing the drug loading capacity as they create imperfections in a highly ordered crystal matrix so that there is enough space for a large amount of drug to fit in productively (Müller, Mäder, Gohla, 2000; Jose et al., 2014).

\section{In vitro drug release study of NLCs}

Drug release study of optimized NLCs was performed in phosphate buffer $\mathrm{pH}$ 7.4. The optimized FLZ-NLCs formulation was subjected to the drug release media for $72 \mathrm{~h}$. The study was performed in triplicates. The release profile of FLZ-NLCs is shown in Figure 3.

Initially there was a rapid release of FLZ from NLCs $(20.30 \pm 2.08 \%$ in first $2 \mathrm{~h})$ and then later the release got retarded. The initial rapid release may be due to the presence of some amount of drug on the surface of the prepared NLCs and then the drug release corresponded to the core of the solid lipid in NLCs. The optimized FLZ-NLCs showed release of $37.34 \pm 2.08 \%$ over a period of $72 \mathrm{~h}$.

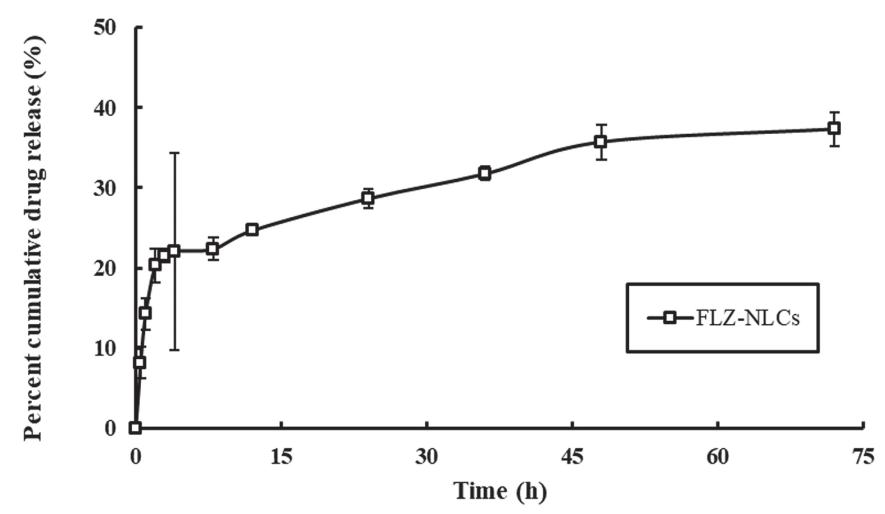

FIGURE 3 - In vitro drug release profile of optimised FLZ-NLCs in phosphate buffer $\mathrm{pH} 7.4$ (data presented as mean $\pm \mathrm{SD}, \mathrm{n}=3$ ). Abbreviation: SD, standard deviation.

\section{CONCLUSION}

In the present study, FLZ loaded NLCs were successfully prepared using ultrasonication emulsion technique by using stearic acid as the solid lipid, castor oil as the liquid lipid and tween 20 as an emulsifier. The NLCs formulation was optimized by applying DoE, and the data was analysed using Design Expert ${ }^{\circledR}$ v.9.0.5.1 software. The particle size, polydispersity index and zeta potential of an optimized FLZ-NLCs was found to be
$359.15 \pm 9.83 \mathrm{~nm}, 0.236 \pm 0.01$ and $-19.25 \pm 0.35 \mathrm{mV}$, respectively. The drug content of optimized NLCs was found to be $102.97 \pm 7.45 \%$ and encapsulation efficiency was found to be $87 \pm 0.59 \%$. In vitro drug release studies of FLZ-NLCs showed $37.34 \pm 2.08 \%$ drug release over a period of $72 \mathrm{~h}$. The above obtained results projected that the prepared FLZ-NLCs may be useful for the treatment of fungal infections.

\section{ACKNOWLEDGEMENTS}

Authors are thankful to Ipca Laboratories, Mumbai, India for providing drug as a gift sample. Authors are grateful to Signet Chemical Corporation Pvt. Ltd., Mumbai for providing poloxamer 188 as a gift sample. Authors also acknowledge the support of Manipal Academy of Higher Education (MAHE), Manipal, Karnataka, India for providing infrastructural facilities.

\section{DISCLOSURE}

The authors declared that there is no conflict of interest in this work.

\section{REFERENCES}

Ameen M. Epidemiology of superficial fungal infections. Clin Dermatol. 2010;28(2):197-201.

Asasutjarit R, Lorenzen SI, Sirivichayakul S, Ruxrungtham K, Ruktanonchai U, Ritthidej GC. Effect of solid lipid nanoparticles formulation compositions on their size, zeta potential and potential for in vitro pHIS-HIV-Hugag transfection. Pharm Res. 2007;24(6):1098-107.

Asasutjarit R, Sorrachaitawatwong C, Tipchuwong N, Pouthai $\mathrm{S}$. Effect of formulation compositions on particle size and zeta potential of diclofenac sodium-loaded chitosan nanoparticles. Int Schol Scient Res Innov. 2013;7(9):568-570.

Balakrishnan B, James NR, Jayakrishnan A. Tween 20-modified poly(vinyl chloride) exhibits enhanced blood-compatability. Polym Int. 2005;54(9):1304-9.

Behtash A, Nafisi S, Maibach HI. New generation of fluconazole: A review on existing researchers and technologies. Curr Drug Deliv. 2017;14(1):2-15.

Cyr TD, Dawson BA, Neville GA, Shurvell HF. Spectral characterization of fluconazole. J Pharm Biomed Anal. 1996;14(3):247-55. 
Das S, Ng WK, Tan RBH. Are nanostructured lipid carriers (NLCs) better than solid lipid nanoparticles (SLNs): Development, characterizations and comparative evaluations of clotrimazole-loaded SLNs and NLCs? Eur J Pharm Sci. 2012;47(1):139-51.

Dutta L, Mukherjee B, Chakraborty T, Das MK, Mondal L, Bhattacharya S, Gaonkar RH, Debnath MC. Lipid-based nanocarrier efficiently delivers highly water soluble drug across the blood-brain barrier into brain. Drug Deliver. 2018;25(1):50416.

Elfiyani R, Amalia A, Pratama SY. Effect of using the combination of tween 80 and ethanol on the forming and physical stability of microemulsion of eucalyptus oil as antibacterial. J Young Pharm. 2017;9(1):S1-4.

Ewing AV, Wray PS, Clarke GS, Kazarian SG. Evaluating drug delivery with salt formation: Drug disproportionation studied in situ by ATR-FTIR imaging and Ramam mapping. J Pharm Biomed Anal. 2015;111:248-56.

Fluconazole. 2017. Drug Bank. [Accessed on April 04, 2017]. Available from: https://www.drugbank.ca/drugs/DB00196.

Gaba B, Fazil M, Khan S, Ali A, Baboota S, Ali J. Nanostructured lipid carrier system for topical delivery of terbinafine hydrochloride. Bull Fac Pharmacy, Cairo Univ. 2015;53(2):14759.

Gaikwad VL, Yadav VD, Dhavale RP, Choudhari PB, Jadhav SD. Effect of carbopol 934 and 940 on fluconazole release from topical gel formulation: A factorial approach. Current Pharma Research. 2012;2(2):487-93.

Garud A, Singh D, Garud N. Solid lipid nanoparticles (SLN): Method, characterization and applications - Review. Int Curr Pharm J. 2012;1(11):384-93.

$\mathrm{Gu}$ and Jian. Characterization of polymeric forms of fluconazole using fourier transform raman spectroscopy. J Pharm Sci. 1995;84(2):1438-41.

Güngör S, Erdal MS, Aksu B. New formulation strategies in topical antifungal therapy. J Cosmet Dermatol Sci Appl. 2013;3(1A):56-65.

Gupta M, Vyas SP. Development, characterization and in vivo assessment of effective lipidic nanoparticles for dermal delivery of fluconazole against cutaneous candidiasis. Chem Phys Lipids. 2012;165(4):454-61.
Havlickova B, Czaika VA, Friedrich M. Epidemiological trends in skin mycoses worldwide. Mycoses. 2008;51(Suppl 4):2-15.

Helal DA, Abd El-Rhman D, Abdel-Halim SA, El-Nabarawi MA. Formulation and evaluation of fluconazole topical gel. Int J Pharm Pharm Sci. 2012;4(Suppl 5):176-83.

Jose S, Anju SS, Cinu TA, Aleykutty NA, Thomas S, Souto EB. In vivo pharmacokinetics and biodistribution of resveratrolloaded solid lipid nanoparticles for brain delivery. Int J Pharm. 2014;474(1-2):6-13.

Kamata T, Umemura J, Takenaka T. Infrared ATR spectra of stearic acid LB films: Intensity enhancement by Au evaporation. Bull Inst Chem Res Kyoto Univ. 1987;65(4):170-8.

Kaur IP, Bhandari R, Bhandari S, Kakkar V. Potential of solid lipid nanoparticles in brain targeting. J Control Rel. 2008;127(2):97-109.

Kelidari HR, Moazeni M, Babaei R, Saeedi M, Akbari J, Parkoohi PI, Nabili M, Gohar AA, Morteza-Semnani K, Nokhodchi A. Improved yeast delivery of fluconazole with a nanostructured lipid carrier system. Biomed Pharmacother. 2017;89:83-8.

Kimura F, Umemura J, Takenaka T. FTIR-ATR studies on Langmuir-Blodgett films of stearic acid with 1-9 monolayes. Langmuir 1986;2(1):96-101.

Kovacevic A, Savic S, Vuleta G, Müller RH, Keck CM. Polyhydroxy surfactants for the formulation of lipid nanoparticles (SLN and NLC): Effect on size, physical stability and particle matrix structure. Int J Pharm. 2011;406(1-2):163-172.

Kumar L, Reddy MS, Shirodkar RK, Pai GK, Krishna VT, Verma R. Preparation and characterization of fluconazole films for the treatment of vaginal candidiasis. Indian J Pharm Sci. 2013;75(5):585-90.

Kumar L, Reddy MS, Verma R, Koteshwara KB. Selection of cryoprotective agent for freeze drying of valsartan solid lipid nanoparticles. Latin Am J Pharm. 2016;35(2):284-90.

Ledeţi I, Vlase G, Vlase T, Şuta LM, Todea A, Fuliaş A. Selection of solid-state excipients for simvastatin dosage forms through thermal and nonthermal techniques. J Therm Anal Calorim. 2015;121(3):1093-1102.

Lee CM, Maibach HI. Deep percutaneous penetration into muscles and joints. J Pharm Sci. 2006;95(7):1405-13. 
Li X, Nie SF, Kong J, Li N, Ju CY, Pan WS. A controlled-release ocular delivery system for ibuprofen based on nanostructured lipid carriers. Int J Pharm. 2008;363(1-2):177-82.

Martins S, Tho I, Souto E, Ferreira D, Brandl M. Multivariate design for the evaluation of lipid and surfactant composition effect for optimisation of lipid nanoparticles. Eur J Pharm Sci. 2012;45(5):613-23.

Merkus JM. Treatment of vaginal candidiasis: Orally of vaginally? J Am Acad Dermatol. 1990;23(3 Pt 2):568-72.

Moazeni M, Kelidari HR, Saeedi M, Morteza-Semnani K, Nabili M, Gohar AA, Akbari J, Lotfali E, Nokhodchi A. Time to overcome fluconazole resistant Candida isolates: Solid lipid nanoparticles as a novel antifungal drug delivery system. Colloid Surf B Biointerfaces. 2016;142:400-7.

Montenegro L, Lai F, Offerta A, Sarpietro MG, Micicchè L, Maccioni AM, Valenti D, Fadda AM. From nanoemulsions to nanostructured lipid carriers: A relevant development in dermal delivery of drugs and cosmetics. J Drug Deliver Sci Technol. 2016;32(Part B):100-112.

Müller RH, Mäder K, Gohla S. Solid lipid nanoparticles (SLN) for controlled drug delivery: a review of the state of the art. Eur J Pharm Biopharm. 2000;50(1):161-77.

Nair AS, Pradeep T, MacLaren I. An investigation of the structure of stearate monolayers on $\mathrm{Au} @ \mathrm{ZrO}_{2}$ and $\mathrm{Ag} @ \mathrm{ZrO}_{2}$ core-shell nanoparticles. J Mater Chem. 2004;14(5):857-62.

Narwal SK, Saun NK, Dogra P, Chauhan G, Gupta R. Production and characterization of biodiesel using nonedible castor oil immobilized lipase from Bacillus aerius. BioMed Res Int. 2015;2015:281934.

Olbrich C, Kayser O, Müller R. Lipase degradation of Dynasan 114 and 116 solid lipid nanoparticles (SLN) - effect of surfactants, storage time and crystallinity. Int J Pharm. 2002;237(1-2):119-28.

Olbrich C, Müller R. Enzymatic degradation of SLN effect of surfactant and surfactant mixtures. Int J Pharm 1999;180(1):31-9.

Pardeike J, Weber S, Haber T, Wagner J, Zarfl HP, Plank $\mathrm{H}$, Zimmer A. Development of an itraconazole-loaded nanostructured lipid carrier (NLC) formulation for pulmonary application. Int J Pharm. 2011;419(1-2):329-38.
Perez M. Gibbs-Thomson effects in phase transformations. Scripta Mater. 2005;52(8):709-12.

Saez V, Souza IDL, Mansur CRE. Lipid nanoparticles (SLN \& NLC) for delivery of vitamin E: A comprehensive review. Int J Cosmetic Sci. 2018:40(2):103-16.

Sanad RA, Abdelmalak NS, Elbayoomy TS, Badawi AA. Formulation of a novel oxybenzone-loaded nanostructured lipid carriers (NLCs). AAPS PharmSciTech. 2010;11(4):1684-94.

Satander-Ortega MJ, Jódar-Reyes AB, Csaba N, BastosGonzález D, Ortega-Vinuesa JL. Colloidal stability of luronic F68-coated PLGA nanoparticles: A variety of stabilisation mechanisms. J Colloid Interfac Sci. 2006;302(2):522-9.

Sawant B, Khan T. Recent advances in delivery of antifungal agents for therapeutic management of candidiasis. Biomed Pharmacotherapy. 2017;96:1478-90.

Selvamuthukumar S, Velmurugan R. Nanostructured lipid carriers: a potential drug carrier for cancer chemotherapy. Lipids Health Dis. 2012;11:159.

Shah R, Eldridge D, Palombo E, Harding I (editors). Composition and structure. In: Lipid nanoparticles: Production, characterization and stability. Heidelberg: Springer International Publishing; 2015. p. 11-22.

Shah R, Eldridge D, Palombo E, Harding I. Optimisation and stability assessment of solid lipid nanoparticles using particle size and zeta potential. J Phys Sci. 2014;25(1):59-75.

Sharma P, Ganta S, Denny WA, Garg S. Formulation and pharmacokinetics of lipid nanoparticles of a chemically sensitive nitrogen mustard derivative: Chlorambucil. Int J Pharm. 2009;367(1-2):187-194.

Silva R, Ferrira H, Little C, Cavaco-Paulo A. Effect of ultrasound parameters for unilamellar liposome preparation. Ultrasonic Sonochem. 2010;17(3):628-32.

Soliman GM. Nanoparticles as safe and effective delivery systems of antifungal agents: Achievements and challenges. Int J Pharm. 2017;523(1):15-32.

Souto EB, Wissing SA, Barbosa CM, Müller RH. Development of a controlled release formulation based on SLN and NLC for topical clotrimazole delivery. Int J Pharm. 2004;278(1):71-7. 
Srinivas NSK, Verma R, Kulyadi GP, Kumar L. A quality by design approach on polymeric nanocarrier delivery of gefitinib: formulation, in vitro and in vivo characterization. Int J Nanomed. 2017;12:15-28.

Trombino S, Mellace S, Cassano R. Solid lipid nanoparticles for antifungal drugs delivery for topical applications. Ther Deliv. 2016;7(9):639-47.
Wolf M, Klang V, Halper M, Stix C, Heuser T, Kotisch H, Valenta C. Monoacyl-phosphotidylcholine nanostructured lipid carriers: Influence of lipid and surfactant content on in vitro skin permeation of flufenamic acid and fluconazole. J Drug Deliver Sci Technol. 2017;41:419-30.

Zamiri R, Zakaria A, Abbastabar H, Darroudi M, Husin MS, Mahdi MA. Laser-fabricated castor oil-capped solver nanoparticles. Int J Nanomed. 2011;6:565-8.

Received for publication on $26^{\text {th }}$ January 2018 Accepted for publication on $30^{\text {th }}$ September 2018 